\title{
Taxonomy of Acinetobacter: the usefulness of $\beta$-D-xyloside xylohydrolase for strain differentiation
}

\author{
W. HANSEN, E. SCHOUTENS, AND E. YOURASSOWSKY \\ From the Service de Biologie Clinique, Hôpital Universitaire Brugmann, 1020 Brussels, Belgium
}

SUMMARY One hundred and twenty-two clinical isolates of Acinetobacter were studied for the presence of $\beta$-galactosidase and of $\beta$-xylosidase, for biochemical characteristics, and for genetic interspecies transformation tests. All strains lacked $\beta$-galactosidase; in contrast, $\beta$-xylosidase was always present in the oxidative strains. This test proved to be of value for separating strains able to form acid from carbohydrates ( $A$. anitratum and $A$. haemolyticus spp haemolyticus) from the non-oxidative strains ( $A$. lwoffi and $A$. haemolyticus spp alcaligenes). However, the genetic relationship of all strains tested warrants further study before Acinetobacters are grouped into clearly defined species.

Beta-D-xyloside xylohydrolase ( $\beta$-xylosidase) is the enzyme involved in the hydrolysis of the o-nitrophenyl- $\beta$-D-xylopyranoside (or of its para-isomer) owing to its specific action on the $\beta-1-4$-xylosebonds. The presence of this enzyme has been demonstrated in various animal tissues (Fisher et al., 1967), in some rumen bacteria (Howard et al., 1960), as well as in some Cytophagaceae (Clermont et al., 1970).

Brisou et al. (1972) recently reported that the demonstration of $\beta$-xylosidase activity was a useful feature for taxonomic differentiation of Enterobacteriaceae, and Richard (1973) used this test for the classification of Klebsiella strains.

The present study is a taxonomic evaluation of the $\beta$-xylosidase test for grouping Acinetobacter strains in defined species: indeed, although there is an increased number of papers dealing with the isolation of Acinetobacter from clinical material as well as with considerations of their pathogenic role in a variety of human infections, the literature is very confusing with regard to taxonomy and nomenclature of the causative organisms.

\section{Material and methods}

MICROBIAL STRAINS

Included in the study were 122 clinical isolates which were assigned to the genus Acinetobacter according to the descriptions given by Brisou and Prévot (1954), Baumann et al., (1968), and Gilardi (1971),

Received for publication 26 January 1977 ie, aerobic, non motile, oxidase-negative, non fermentative, Gram-negative coccobacilli. The origins $\mathbb{\mathscr { D }}$ of the strains examined were as follows: urine $\vec{v}$ (27 strains), sputum (25 strains), blood cultures $\exists$ (10 strains), wounds and leg ulcers (30 strains pleural and peritoneal fluids (9 strains), transtrache aspirations (4 strains), vaginal samples (3 strains), cerebrospinal fluid (2 strains), lung, aortic valve, lymph node, and placenta (1 strain each), and environmental samples (8 strains).

METHODS OF EXAMINATION

For the detection of $\beta$-D-galactoside-galactohydrolase ( $\beta$-galactosidase) a heavy suspension of cells grown on Kligler medium was made in test tubes containing $0.5 \mathrm{ml}$ of saline solution and incubated for 24 hours at $37^{\circ} \mathrm{C}$ in the presence of an ONPG disk (Bio-Mérieux).

Detection of $\beta$-xylosidase was performed according to the method of Brisou et al. (1972). Although similar results were obtained by these authors with either ortho- or para-nitro-phenyl- $\beta$-D-xylopyrano- $\frac{T}{O}$ side (PNPX), the latter drug was chosen because of its better solubility. A heavy suspension of cells $\tilde{N}$ grown on heart infusion agar was made in test $N$ tubes containing $0.5 \mathrm{ml}$ of saline solution and incu- N bated for 24 hours at $37^{\circ} \mathrm{C}$ in the presence of a PNPX disk. These disks were prepared in our laboratory as follows. Paper disks (diameter $1 \mathrm{~cm}$ )

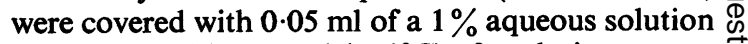
of PNPX and kept cool $\left(+4^{\circ} \mathrm{C}\right)$ after drying.

Oxidation of $1 \%$ carbohydrates was studied in OF Basal medium (BBL) according to the method of 
Hugh and Leifson (1953): one pentose (xylose) and three hexoses (galactose, glucose, and mannose) were tested.

Transformation of lactose into lactobionic acid was tested by the method of Aiken et al. (1956) using Purple-Agar-Base (Difco) supplemented with $10 \%$ lactose.

Gelatinase production was tested by the method of Frazier (1926). Tests for lecithinase production were performed on Trypticase Soy Agar supplemented with $100 \mathrm{ml} / \mathrm{l}$ of a $50 \%$ saline solution of egg-yolk. Caseinase production was established by cultivation of each strain on Trypticase Soy Agar supplemented with $15 \%$ fresh skimmed milk.

Growth characteristics were observed on SS agar (Salmonella-Shigella-Agar, Difco) after 24 and 48 hours' incubation at $37^{\circ} \mathrm{C}$. Fifty strains were screened for their ability to utilise lsactic acid as sole carbon and energy source when grown in the S-2 mineral solution of Monod and Wollman (1947) with $1.5 \%$ agar added and a final concentration of $0.25 \%$ lactic acid.

These strains were also tested for their ability to transform a stable competent auxotroph of Acinetobacter (strain trp E 27) according to the method of Juni (1972), modified by Brooks and Sodeman (1974).

\section{Results}

As shown in Table 1, all strains of Acinetobacter examined lacked $\beta$-galactosidase; however, $\beta$-xylosidase was present in every strain able to attack carbohydrates oxidatively.

All strains of $A$. haemolyticus produced gelatinase and caseinase whereas these were negative characters for $A$. anitratum and $A$. lwoffi. All but two strains of $A$. haemolyticus produced lecithinase and all but two grew on SS agar; however, these two tests were of lesser value in separating $A$. haemolyticus from $A$. anitratum and $A$. lwoffi as they were also positive characters for some strains of the latter two subgroups.

Ability to utilise lactic acid as the sole carbon and energy source was tested on only 50 of the strains studied; it was a constant feature of $A$. anitratum and of all but one strain of $A$. lwoffi. The DNA samples from 50 strains of Acinetobacter used in this study, whatever their metabolic or enzymatic characteristics, were able to transform the competent auxotroph trp E 27 to prototrophy (Table 2). Other Gram-negative strains representing various genera-Pseudomonas spp, Enterobacteriaceae, Erwinia spp-failed to give a positive transformation test.

\section{Discussion}

The genus Acinetobacter was first defined in 1954 by Brisou and Prevot, and further confirmed by Baumann et al. in 1968. It is now adopted by most of the taxonomists. However, the literature dealing with the subgroups constituting this entity is very confusing: some authors recognise only one species (Henriksen, 1973) while others admit as many as 16 different species (Brisou and Prévot, 1954). Moreover, identical organisms are known under various names, while others received the same label, although they actually are considered to belong to different genera.

In the present work we adopted the nomenclature of Gilardi (1971) revised from that of Stenzel and Mannheim (1963): the genus Acinetobacter is divided into four species on the basis of differences observed in acid production from carbohydrates, proteolysis, haemolysis, growth characteristics, and utilisation of organic compounds as sole sources of carbon.

Table 1 Characteristics of Acinetobacter strains

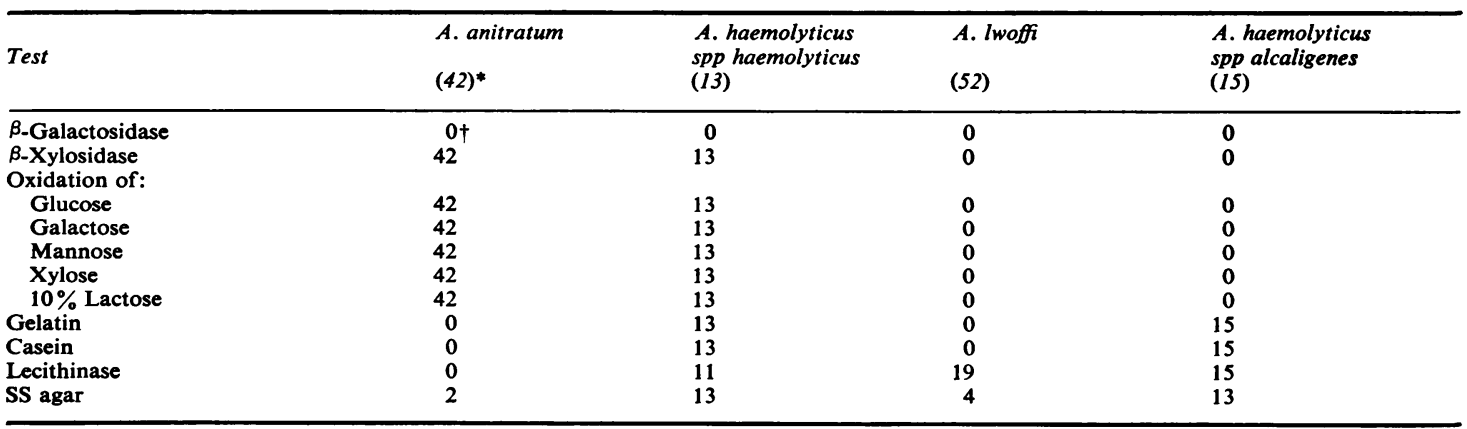

* Number of strains examined.

$\dagger$ Number of strains positive for each character. 
Table 2 Characteristics of Acinetobacter strains

\begin{tabular}{lllll}
\hline & A. anitratum & $\begin{array}{l}\text { A. haemolyticus } \\
\text { spp haemolyticus } \\
(9)\end{array}$ & $\begin{array}{l}\text { A. lwoffi } \\
(17)^{*}\end{array}$ & $\begin{array}{l}\text { A. haemolyticus } \\
\text { spp alcaligenes } \\
(5)\end{array}$ \\
\hline $\begin{array}{l}\text { Assimilation of lactic acid as sole } \\
\text { source of carbon }\end{array}$ & $17 \dagger$ & 0 & 18 & 0 \\
$\begin{array}{c}\text { Genetic transformation of competent } \\
\text { Acinetobacter strain TRP E 27 }\end{array}$ & 17 & 9 & 19 & 5 \\
\hline
\end{tabular}

* Number of strains examined.

†Number of strains positive for each character

As pointed out by others (Henriksen, 1973; Lapage et al., 1973), none of the strains of Acinetobacter, even the glucidolytic ones, produces $\beta$-galactosidase. In contrast, the demonstration of $\beta$-xylosidase in all strains able to produce acid from carbohydrates (whereas the nonglucidolytic strains always lack this enzyme) is a helpful characteristic to enable the genus to be divided into different subspecies. Indeed, if the oxidation-fermentation test is of great taxonomic value, demonstration of the enzyme which catalyses the reaction, or of the end product resulting from that reaction, is a far more reliable technique than an indicator colour change induced by acid production, to attest the type of carbohydrate breakdown observed.

Many workers take into account only the acid production from glucose for the separation of strains of Acinetobacter into two subgroups: $A$. lwoffi and $A$. anitratum $=A$. calcoaceticus. In 1956, Piechaud et al., on the basis of the gelatinase test, suggested the epithets 'liquefaciens' for the proteolytic strains and 'nonliquefaciens' for the strains which do not produce gelatinase.

Stenzel and Mannheim (1963) and Gilardi (1971) consider the demonstration of haemolysis as reliable as the production of other extracellular enzymes when classifying Acinetobacter strains. Although we studied this character, we did not take our results into consideration as, in our experience, haemolysis was sometimes difficult to detect. Moreover, as haemolysin produced by Acinetobacter strains (different from that of $\beta$-haemolytic streptococci) is a phospholipase $C$, we demonstrated it when testing for the presence of lecithinase.

With the combined use of the $\beta$-xylosidase test (which is easily performed as a 'routine' service by any clinical laboratory) and gelatinase (and/or caseinase) production, Acinetobacter strains can be distributed into four subgroups: among the $\beta$-xylosidase positive strains, the gelatinase negative group ( $A$. anitratum) and the gelatinase positive group (A. haemolyticus, spp haemolyticus), among the $\beta$-xylosidase negative strains, the gelatinase negative group (A. lwoffi) and the gelatinase positive group
(A. haemolyticus, spp alcaligenes). Recognition of four subgroups is also corroborated by other tests, such as growth on SS agar and utilisation of lactic acid as the sole source of carbon and energy.

However, transformation tests demonstrate a genetic relationship of all strains tested, whatever their physiological characteristics may be. We agree with Juni (1972) that further studies (nucleic acid hybridisation, isoenzymes) are warranted before Acinetobacters are grouped into clearly defined species. At the present time it is more reasonable to adopt the classification of Henriksen (1973), who recognises but one species $(A$. anitratum $=A$. calcoaceticus) among which several biotypes can be demonstrated.

\section{References}

Aiken, M. A., Ward, M. K., and King, E. O. (1956). A study of a group of gram negative bacteria resembling the tribe Mimeae (DeBord). Public Health Laboratory, 14, 126-136.

Baumann, P., Doudoroff, M., and Stanier, R. Y. (1968) A study of the Moraxella group. II. Oxidase-negative species (genus Acinetobacter). Journal of Bacteriology, 95, 1520-1541.

Brisou, J., and Prévot, A. R. (1954). Études de systématique bactérienne. $\mathrm{X}$. Révision des espèces réunies dans le genre Achromobacter. Annales de l'Institut Pasteur (Paris), 86, 722-728.

Brisou, B., Richard, C., and Lenriot, A. (1972). Intérêt taxonomique de la recherche de la $B$-xylosidase chez les 'Enterobacteriaceae'. Annales de l'Institut Pasteur (Paris), 123, 341-347.

Brooks, K., and Sodeman, T. (1974). Clinical studies on a transformation test for identification of Acinetobacter (Mima and Herellea). Applied Microbiology, 27, 1023-1026.

Clermont, S., Charpentier, M., and Percheron, F. (1970). Polysaccharidases de Sporocytophaga myxococcoides; bêta-mannanase, cellulase et xylanase. Bulletin de la Société de Chimie Biologique, 52, 1481-1495.

Fisher, D., Whitehouse, M. W., and Kent, P. W. (1967). Beta-xylosidase and beta-galactosidase activities of mammalian connective tissues and other sources. Nature, 213, 204-205. 
Frazier, W. C. (1926). A method for detection of changes in gelatin due to bacteria. Journal of Infectious Diseases, 39, 302-309.

Gilardi, G. L. (1971). Characterization of nonfermentative nonfastidious Gram negative bacteria encountered in medical bacteriology. Journal of Applied Bacteriology, 34, 623-644.

Henriksen, S. D. (1973). Moraxella, Acinetobacter, and the Mimeae. Bacteriological Reviews, 37, 522-561.

Howard, B. H., Jones, G., and Purdom, M. R. (1960). The pentosanases of some rumen bacteria. Biochemical Journal, 74, 173-180.

Hugh, R., and Leifson, E. (1953). The taxonomic significance of fermentative versus oxidative metabolism of carbohydrates by various Gram negative bacteria. Journal of Bacteriology, 66, 24-26.

Juni, E. (1972). Interspecies transformation of Acinetobacter: genetic evidence for a ubiquitous genus. Journal of Bacteriology, 112, 917-931.

Lapage, S. P., Efstratiou, A., and Hill, L. R. (1973).
The ortho-nitrophenol (ONPG) test and acid from lactose in Gram-negative genera. Journal of Clinical Pathology, 26, 821-825.

Monod, J., and Wollman, E. (1947). L'inhibition de la croissance et de l'adaptation enzymatique chez les bactéries infectées par le bactériophage. Annales de l'Institut Pasteur (Paris), 73, $937-956$

Piechaud, D., Piechaud, M., and Second, L. (1956). Variétés protéolytiques de Moraxella lwoffi et de Moraxella glucidolytica (Bact. anitratum). Annales de l'Institut Pasteur (Paris), 90, 517-522.

Richard, C. (1973). Etude antigénique et biochimique de 500 souches de Klebsiella. Annales de Biologie Clinique, 31, 295-303.

Stenzel, W., and Mannheim, W. (1963). On the classification and nomenclature of some non-motile and coccoid diplobacteria, exhibiting the properties of Achromobacteriaceae. International Bulletin of Bacteriological Nomenclature and Taxonomy, 13, 195-200. 